\title{
Pedagogia e andragogia na construção da educação de jovens e adultos
}

Rose Mary Kern Martins ${ }^{1}$

\begin{abstract}
Resumo
Esse texto revela a necessidade de novos olhares sobre a forma de ensinar o adulto durante a alfabetização em salas de Educação de Jovens e Adultos (EJA). Cabe ao professor de EJA considerar cultura, espaço, angústias e prazer, a fim de criar condições que levem o aluno a refletir sobre a importância do aprendizado e sua utilização na sociedade, trazendo para a sala de aula diferentes formas de pensar, levantando questionamentos que provoquem os alunos a refletir sobre o porquê de estarem aprendendo e de que forma esse aprendizado poderá ser utilizado em benefício próprio. A EJA não pode ser considerada como uma ação reparadora que necessita resgatar o tempo perdido durante a ausência na escola do aluno. A educação de adultos requer mais que métodos de ensino e material pronto e acabado. Sobretudo, deve-se considerar a bagagem diversificada dos alunos que necessita ser trabalhada em sala de aula e enriquecida pelo currículo escolar e seus conteúdos. A Andragogia, característica da aprendizagem de pessoas adultas, difere da Pedagogia por possuir uma didática voltada especificamente para jovens e adultos com contextos educativos muito heterogêneos e diversificados. Contribui para o entendimento de que tal diversidade, na EJA, engloba três funções, quais sejam: a reparadora, pois permite o retorno à sala de aula desse jovem/adulto; a equalizadora, por permitir que ele volte ao ponto de onde parou, sem qualquer prejuízo; e a função permanente, que propicia a atualização do conhecimento, aquele que vai acompanhá-lo pelo resto de suas vidas e pode ser chamado de qualificadora.
\end{abstract}

\section{Palavras-chave}

EJA. Pedagogia. Andragogia.

1. Graduada em Pedagogia pela Universidade Federal de Juiz de Fora, professora de Linguagens, Códigos e suas Tecnologias na rede pública municipal de ensino de Uberlândia. E-mail: kkern9@hotmail.com. 


\title{
Pedagogy and andragogy in construction education youth and adults
}

Rose Mary Kern Martins*

\begin{abstract}
The text reveals the need for new perspectives on how to teach adult literacy in classrooms for the Education of Youth and Adults (EJA). The teacher has to consider culture of EJA, space, anguish and pleasure in order to create conditions that allow students to reflect on the importance of learning and its use in society bringing to the classroom different ways of thinking, raising questions that provoke students to think about why this learning and how this learning can be used to their advantage. EJA cannot be considered as a remedial action that needs to recover the time lost during the student's absence from school. Adult education requires more than teaching methods and materials ready and finished, especially considering the luggage diverse students that need to be worked into the classroom curriculum and enriched by its contents. The Andragogy, characteristic of adult learning, the pedagogy differs by having a didactic facing youth and adult educational contexts with very heterogeneous and diverse. Contributes to the understanding that such diversity in adult education encompasses three functions which are: restorative, it allows the return to the classroom this youth/adult, the equalizer by allowing him to return to the point where you left off without any permanent damage and function that provides the updating of knowledge, one that will accompany you for the rest of their lives and can be called qualifying.
\end{abstract}

\section{Keywords}

EJA. Pedagogy. Andragogy.

\footnotetext{
* Graduated in Pedagogy at the Federal University of Juiz de Fora, professor of Languages, Codes and its
} Technologies in the municipal teaching system of Uberlândia. E-mail: kkern9@hotmail.com. 


\section{Introdução}

Pensar a Educação de Jovens e Adultos (EJA) como sendo uma ação de resgate ou devolução de algo que foi negado àqueles que não puderam concluir ou mesmo adentrar em um curso de alfabetização é um dever de todos, porque muitos sonhos foram interrompidos, trocados por outros. Estudar não pode ser um sonho, uma vez que é um direito de todo cidadão desse país. O professor de EJA deve pensar que é o mediador e provocador cognitivo de novos conhecimentos que serão repartidos e divididos entre ele e os alunos e vice-versa, respeitando, assim, o educando como ser humano (PICONEZ, 2006). Por meio de suas dúvidas, angústias, timidez e outros sentimentos responsáveis por suas ações e reações, o professor apresenta condições de avaliar as necessidades de aprendizagem de cada aluno. Portanto, ensinar já não é mais levar o conhecimento para a sala de aula e, sim, enriquecer e valorizar os conhecimentos dos estudantes, o que significa adequar as metodologias tradicionais aos conceitos andragógicos que levarão à construção coletiva dos conhecimentos a partir dos referenciais de vida deles, tornando o aprendizado mais agradável e contextualizado.

Diferente de uma sala regular, a EJA requer outros olhares. Para tanto, é necessário buscar conhecimento tal qual um professor pesquisador. O tema Andragogia não tem sido muito explorado ou estudado no país, assim como temas relacionados à Educação de Jovens e Adultos; mas apresenta princípios que atraem aqueles educadores que buscam alternativas de ensino diferentes dos moldes de educação na EJA.

De acordo com definição creditada, na década de 1970, a Malcolm Knowles, Andragogia é a arte ou ciência de orientar adultos a aprender. De origem grega, a palavra "andragogia" tem como significado: andros- adulto e gogos-educar. Em contraposição à Pedagogia (do grego paidós, criança), que se refere à educação de crianças, a Andragogia é a arte de ensinar adultos, sendo um modelo de educação que busca compreender o adulto dentro da escola, rompendo com aqueles padrões apresentados pela Pedagogia.

A Andragogia corresponde à ciência que estuda as melhores práticas para orientar adultos a aprender. É preciso considerar que a experiência é a fonte mais rica para a aprendizagem de adultos. Estes, por sua vez, são motivados a aprender conforme vivenciam necessidades e interesses que a aprendizagem satisfará em sua vida.

O modelo andragógico baseia-se nos seguintes princípios:

1. Necessidade de saber: adultos carecem saber por que precisam aprender algo e qual o ganho que terão no processo.

2. Autoconceito do aprendiz: adultos são responsáveis por suas decisões e por suas vidas, portanto querem ser vistos e tratados, pelos outros, como capazes de se autodirigir.

3. Papeldasexperiências: paraoadulto, suas experiências são a base de seu aprendizado. As técnicas que aproveitam essa amplitude de diferenças individuais serão mais eficazes.

4. Prontidão para aprender: o adulto fica disposto a aprender quando a ocasião exige algum tipo de aprendizagem relacionado a situações reais de seu dia a dia.

5. Orientação para aprendizagem: o adulto aprende melhor quando os conceitos apresentados estão contextualizados para alguma aplicação e utilidade. 
6. Motivação: adultos são mais motivados a aprender por valores intrínsecos: autoestima, qualidade de vida, desenvolvimento.

Na Andragogia, a aprendizagem é focada mais naquilo que é necessário à vivência do aluno na sociedade, com propostas de atividades que envolvem ações do cotidiano que irão ajudá-lo a enfrentar problemas reais (surgidos na vida pessoal de qualquer ser humano), uma vez que é centrada na aprendizagem e não somente no ensino. Sendo assim, o aluno é um agente de sua aprendizagem, interagindo e se apropriando de saberes que contribuem para sua autonomia.

Para entender melhor a Andragogia, Knowles (1991 apud NOGUEIRA, 2004, p. 4) revela as diferentes formas de ensinoaprendizagem que compreende a Pedagogia e a Andragogia.

Quadro 1: Formas de ensino-aprendizagem que compreendem a Pedagogia e a Andragogia.

\begin{tabular}{|c|c|c|}
\hline \multirow{2}{*}{$\begin{array}{l}\text { Processo de ensino } \\
\text { Aprendizagem }\end{array}$} & \multicolumn{2}{|c|}{ Perspectiva } \\
\hline & Pedagogia & Andragogia \\
\hline $\begin{array}{l}\text { Elaboração do plano de } \\
\text { aprendizagem }\end{array}$ & pelo professor & $\begin{array}{l}\text { pelo auxiliador de aprendizagem e } \\
\text { pelo aprendente }\end{array}$ \\
\hline $\begin{array}{c}\text { Diagnóstico de } \\
\text { necessidades }\end{array}$ & pelo professor & $\begin{array}{l}\text { pelo auxiliador de aprendizagem e } \\
\text { pelo aprendente }\end{array}$ \\
\hline $\begin{array}{l}\text { Estabelecimento de } \\
\text { objetivos }\end{array}$ & pelo professor & por meio de negociação mútua \\
\hline $\begin{array}{l}\text { Tipologias de planosde } \\
\text { aprendizagem }\end{array}$ & $\begin{array}{l}\text { planos de conteúdos } \\
\text { organizados de acordo com } \\
\text { uma sequência lógica }\end{array}$ & $\begin{array}{l}\text { diversos planos de aprendizagem } \\
\text { (e.g. contratos de aprendizagem, } \\
\text { projetos de aprendizagem) } \\
\text { sequenciados pela prontidão dos } \\
\text { aprendentes }\end{array}$ \\
\hline $\begin{array}{l}\text { Técnicas de (ensino) } \\
\text { aprendizagem }\end{array}$ & técnicas transmissivas & técnicas ativas e experienciais \\
\hline Avaliação & $\begin{array}{c}\text { pelo professor; } \\
\text { referências a normas; } \\
\text { por meio de pontuação, } \\
\text { notas }\end{array}$ & $\begin{array}{c}\text { pelo aprendente; } \\
\text { referência a critérios; } \\
\text { por meio da validação dos } \\
\text { companheiros, facilitador de } \\
\text { aprendizagem e peritos na área. }\end{array}$ \\
\hline
\end{tabular}

Fonte: Nogueira (2004, p. 4).

O indivíduo adulto, segundo Oliveira (2011, p. 20), quando colocado em uma situação em que se vê obrigado a fazer algo, se sente oprimido, recuado e isso não é, de forma alguma, uma maneira apropriada de se transmitir conhecimento. No modelo andragógico de educação, o professor norteará o aluno a estudar com mais liberdade, porém com responsabilidade. Isso porque, assim, ele será capaz de interpretar as situações em 
que vive baseado em sua própria experiência de vida. Assim, o aluno age de maneira crítica, com liberdade de escolha e mais autonomia, sentindo-se capaz de questionar coisas simples como, por exemplo, uma medicação prescrita pelo médico, pois adquiriu conhecimento tanto por meio de sua própria vivência como por sua maturidade escolar.

Neste modelo, o aluno negocia com o professor, argumenta e discute, acabando, assim, com o monólogo. O professor trabalha a autonomia do adulto, levando-o a conhecer outras formas de explicação, pois ao invés de uma aula em que os textos e monólogos estão sempre presentes, o professor revela, por meio de vídeos, fotografias, peças teatrais e outras atividades, aquilo que uma explicação em monólogo faria.

$\mathrm{Na}$ educação de uma sala EJA, os conhecimentos prévios, que muitos já adquiriram em sua vida, facilitam o processo de ensino-aprendizagem, podendo resumir os monólogos ou transformá-los em diálogos.

As preferências e hábitos do adulto podem sofrer influência durante o seu período de alfabetização, uma vez que o mundo que ele conhecia antes, agora pode ser visto não apenas com os seus olhos, mas com suas interpretações e compreensões dos significados que cada texto, cada palavra que lê, faz sentido em seu viver.

Embora também aconteça com a criança, para o adulto as compreensões fazem-se muito mais a partir da "leitura do mundo" devido à vivência maior desse adulto. Claro que, ao olharmos para a educação e a alfabetização de adultos, primeiro veremos a infantil, pois foi a que primeiro surgiu. Se, no entanto, não podemos transportá-la para a sala de aula, podemos revelar como surgiram algumas práticas pedagógicas de ensino sob outros olhares.

Deacordocom Soares (2003) "letramento" e "letrar" são palavras encontradas apenas em um dicionário do século passado (uma vez que são caracterizadas como antigas), mas ainda muito utilizadas na educação. De acordo com ao autor, a palavra "letramento" veio da língua inglesa (literacy), originada do latim littera, que quer dizer "letra", acrescido do sufixo "-cy", que denota qualidade, condição, estado, fato de ser. Literacy ou letramento, então, é a condição que o grupo ou individuo adquire como consequência de ter se apropriado da leitura e da escrita, além de colocar em prática aquilo que aprende, trazendo resultados positivos e significativos para a sociedade como um todo, percebidos em vários âmbitos (subentende-se, assim, que o domínio da escrita tem implicações sociais, culturais, políticas, econômicas, cognitivas e linguísticas). Alfabetização e Letramento em uma sala EJA é um desafio diário e a Andragogia chega para agregar conhecimento ao pedagogo, preparando-o para a realidade de uma sala EJA, que é bem diferente de uma do ensino regular, em que as faixas etárias são equitativas. Então, o que trabalhar em uma sala EJA? Que projetos poderiam interessar esse público? O público jovem e adulto, por ter vivenciado experiências ao longo de sua vida, necessita de acompanhamento e direcionamento dos saberes já adquiridos, além, é claro, daqueles curriculares. O professor precisa saber quais são as condições de vida dos alunos para, então, trabalhar conteúdos extracurriculares que vão ao encontro de suas reais necessidades. Por isso, é importante que o professor trabalhe saberes que possam auxiliar situações vividas no cotidiano desses alunos.

$\mathrm{O}$ educador de EJA pode levar para a sala atividades como: preenchimento de ficha cadastral de crediário, de locação, de conta bancária, de cartão de crédito; subscrição de envelope, de depósito bancário; leitura e compreensão de extrato bancário ou de outra entidade financeira, objetivando também que o aluno venha a conhecer as formas de grafia que podem ser utilizadas como a letra de forma, normalmente usada no preenchimento de formulários, e a discursiva, que é a do 
cotidiano escolar e social. Atividades como essas podem ajudar o aluno em situações em que, muitas vezes, ele necessita de intervenção de terceiros, mesmo se tratando de tarefas tão simples ao aluno alfabetizado e letrado. Além desses exercícios, os alunos poderão trazer suas dúvidas e propostas. Por meio dessas propostas, a alfabetização e o letramento juntam-se e acompanham o adulto em seu dia a dia.

Ter um olhar para além da sala de aula também é de suma importância ao educador de EJA, porque o ser humano vive em sociedade, mas, muitas vezes, por falta de tempo, esquecese de olhar à sua volta e descobrir outras fontes de conhecimentos e experiências. Por isso, o professor precisa pensar em atividades para além dosmuros escolarescomo, por exemplo, visitação a museus, parques, zoológicos, teatro e praças.

Também, uma aula mais participativa aumenta as possibilidades de melhorar a autoestima do aluno e sua capacidade de trabalhar em grupo e de se relacionar com seus colegas, além da autonomia que o professor deve estimular no aluno por meio de escolhas de atividades, projetos de aprendizagem e diálogo aberto.

Assim é o modelo de aprendizagem dentro da Andragogia, bem diferente da Pedagogia usada em uma sala regular. Nogueira (2004), citando Knowles (1980), refere-se aos alunos como "aprendentes":

Knowles (1980) refere ainda que cabe ao facilitador da aprendizagem verificar quais os pressupostos adequados a uma dada situação. Quando os aprendentes são dependentes, quando não possuem experiência prévia na área, quando não compreendem a relevância de determinado conteúdo nas suas tarefas diárias, quando necessitam de acumular rapidamente conhecimentos para atingir certas performances; então o modelo pedagógico é o mais adequado (NOGUEIRA, 2004, p. 5).

Ao se apropriar dos métodos utilizados na educação infantil pela Pedagogia, o professor, em uma sala de EJA, precisa observar se está alterando a metodologia, a fim de não infantilizar a aula e o público. Entretanto, se sentir que há necessidade de revelar mais detalhes sobre o conteúdo proposto, esse professor acabará utilizando recursos de aprendizagem de uma sala regular, procurando trabalhar com assuntos pertinentes àquela faixa etária. Por isso, o educador não deve seguir apenas o modelo utilizado pela Andragogia, acreditando que o adulto, por ter mais experiência, não necessita de material concreto para uma melhor compreensão do conteúdo proposto.

Ao trabalhar as práticas pedagógicas em uma sala EJA, o professor deve estar atento para não criar nenhum tipo de constrangimento que leve o aluno a se sentir diminuído, por isso essas práticas devem se adequar ao processo de ensino-aprendizagem na educação de jovens e adultos, já que eles viveram mais que as crianças e já "leram" muita coisa do mundo, o que aumenta a chance de sua bagagem estar repleta de saberes. Por exemplo, o professor de uma sala de EJA, acostumado com uma sala regular de alfabetização, precisa tomar cuidado para não utilizar, naquela, frases costumeiramente utilizadas nesta, pois pode confundir os alunos. Imagine um professor pedindo aos alunos de EJA que levem um caderninho na próxima aula, muito provavelmente eles levarão uma caderneta. Essa e outras situações podem ser evitadas ao se trabalhar a forma diminutiva e aumentativa das palavras, apresentando, por exemplo, uma lata de extrato grande e outra pequena, ou seja, uma lata e uma latinha.

Segundo Alves (2003, p. 48), “o corpo aprende para viver. É isso que dá sentido ao conhecimento. $\mathrm{O}$ que se aprende são ferramentas, possibilidades de poder. $\mathrm{O}$ corpo não aprende por aprender. Aprender por aprender é estupidez". Ensinar ao aluno conteúdos por estarem no currículo ou em seu livro didático, sem que estes conteúdos 
nada tenham a ver com a realidade do aluno, ou ainda que não venham acrescentar algo que lhe dará prazer ou fará alguma diferença em sua vida, torna-se insípido para o aluno, que, muitas vezes, prefere ficar conversando fora da escola até que termine tal disciplina por achar a aula sem graça ou chata. Cabe ao professor estimular o aluno e isso é um dos aspectos da Andragogia, que trabalha o conteúdo como algo que sirva para a vida do aluno, algo que lhe permitirá possibilidades de crescimento em seu meio. Cabe também a ele propor mudanças de atitude, estimulando-o a pensar o ambiente em que vive e suas formas de preservar ou melhorar a sua qualidade de vida. Nesse sentido, ressalta Paulo Freire (2006, p. 30):

[..] Por que não aproveitar a experiência que tem de viver os alunos em área da cidade descuidada pelo poder público para, por exemplo, discutir a poluição dos riachos e dos córregos e dos baixos níveis de bem-estar das populações, os lixões e os riscos que oferecem à saúde das gentes [...].

Projetos que levem o aluno a pensar ludicamente podem ser trabalhados em sala de aula, pois existem diversas ferramentas que auxiliam o professor na construção do conhecimento, diferentes daqueles propostos didaticamente. Trabalhar o meio ambiente por meio de projetos pode ser uma alternativa, mas outras formas de aprendizado estão contidas em ferramentas que podem ser utilizadas: jogos como: bingo, quebra-cabeça, baralho de palavras ou sílabas e outros encontrados em lojas apropriadas ou no computador, que é outra ferramenta bastante útil no aprendizado.

Além desses recursos, uma forma prazerosa de levar conhecimento é a reciclagem, que traz para a sala de aula o despertar para a criatividade do aluno, em busca de compreender as diversas alterações que estão ocorrendo no mundo atual.

\section{Uma experiência com a Educação de Jovens e Adultos}

Em uma sala EJA, a experiência no ensino de Matemática envolve números, cálculos e também noção de tempo e espaço. Como estagiária de uma sala EJA de alunos especiais, com estudantes de diferentes faixas etárias, ao trabalhar as horas, o tempo e sua significação, levei para a sala de aula pequenas caixas de papelão que serviram de base para colar o material sintético EVA de cor amarela, cola e espiral de plástico usado para encadernação. $\mathrm{O}$ material foi confeccionado pelos alunos, dentre eles, relógios de $15 \mathrm{~cm}$ de diâmetro e um de 30 $\mathrm{cm}$ com a finalidade de trabalhar os números, as horas e a importância do tempo em nossas vidas.

$\mathrm{Na}$ sequência da atividade, cada aluno ficou com um relógio na carteira e a professora com o maior, para mostrar que horas eles todos tinham que direcionar os seus ponteiros. Um pequeno texto foi produzido com os educandos, revelando o valor dos dois ponteiros mais significativos em um relógio analógico, ou seja, o ponteiro da hora e o do minuto. O texto continha o seguinte: para saber a hora ver, temos que os ponteiros obedecer. O grande para o minuto, o pequeno para hora. O ponteiro maior foi apresentado primeiro, justamente pelo fato de chamar a atenção pelo tamanho, então o seu valor foi logo definido e a ideia deu certo, incluindo a participação e o aprendizado, que ocorreu de forma surpreendente. A apresentação das horas deu-se de forma lúdica com perguntas do tipo: a que horas é o lanche da escola?; a que horas a professora acorda no domingo? e nos dias letivos?, perguntas feitas em relação a cada aluno.

A deficiência está, muitas vezes, na carência de bens materiais, o que não impede o aluno de aprender novas formas de comunicação e tecnologias, utilizadas no ensino-aprendizagem, sem que isso modifique o aspecto cultural da linguagem do aluno EJA, 
pois, com suas diferentes maneiras de ser e sua cultura enraizada em diversas regiões no país, o brasileiro é múltiplo em suas linguagens e jargões. Soares (2008, p. 31) revela-nos que:

A ideologia da deficiência cultural veio apresentar uma confortável resposta a essa ameaça: ocultando a verdadeira causa da discriminação - a desigual distribuição da riqueza numa sociedade capitalista -, atribui a deficiências culturais e linguísticas da criança das camadas populares o seu fracasso na escola. As falhas são, assim, da criança, de sua família, de seu contexto cultural; a inadequação está na criança, não na sociedade nem na escola.

Apresentar livros às crianças não é a mesma coisa que os apresentar aos adultos, pois, na pequena infância, a criança ainda está em uma fase de desenvolvimento, tanto físico quanto intelectual, tornando-se mais fácil levála a sonhar e a imaginar paisagens, personagens e suas falas. Os adultos, por sua vez, necessitam de outros tipos de gêneros que, além de atrair sua atenção e estímulo para a leitura e a escrita, pode ser um facilitador de seu cotidiano. Concluindo a graduação em Pedagogia, em meio a um dos estágios na educação infantil numa sala com crianças de três a cinco anos trabalhei leitura por meio da oralidade. A proposta era despertar a criança para o mundo da fantasia e da imaginação por meio de livros da literatura infantil que contivessem pequenos textos e figuras coloridas. Cada um escolhia o livro que queria manusear, inclusive o professor. Após o manuseio e leitura das figuras, o educador lia a história, enfatizando bem as gravuras e aproveitando para trabalhar as cores, natureza, ecologia e meio ambiente. Em seguida, cada criança, espontaneamente, contava a sua história, enfatizando as mesmas coisas que o seu professor. No começo, nem todos os alunos se sentiram à vontade para falar, mas depois de duas semanas todos participavam. A atividade permitiu verificar as preferências, tanto de gêneros e personagens quanto de cores que continham cada livro.

Como já dito, trabalhar com crianças é uma coisa, com adultos é outra. Então, em uma sala de EJA, pode ser negociado com os alunos trabalhar com música, poesias, poemas e pequenos trechos de livros de sua preferência. Contar histórias e ouvi-las pode ser outro caminho que o professor pode utilizar para motivar o aluno adulto a contar fatos de sua vida ou "casos" que aconteceram em tempos remotos, podendo até propor trazer uma pessoa da comunidade que saiba contar fatos ocorridos nela. Valorizar o grupo, a sociedade em que vivem, suas historias e memórias é um ato que pode levar o professor a (re)descobrir seus alunos, trabalhando com eles seus valores, seu passado, seus sonhos e desejos, sendo um norteador não apenas de conhecimento, mas de sonhos, de como ensinar a sonhar e a valorizarse diante do mundo e de si próprio. Por isso, é importante criar oportunidades para que o grupo se relacione, propondo atividades que propiciem o desenvolvimento de coleguismo e união, pois cabe ao professor perceber aqueles que estão com dificuldades não apenas cognitivas, mas emocionais de seguir em frente com segurança e com sonhos em suas mãos.

Ao perceber o aluno como um ser que tem valor e que suas memórias falam muito e que podem auxiliar na trajetória não apenas dele, mas de todos os que o cercam pode desenvolver motivação e esperança de uma vida melhor, com um futuro que pode ser abraçado sem receio, apesar das adversidades que o mundo possa oferecer. Alves (2003, p. 58) afirma que:

Não é coisa que eu tenha inventado. Me foi ensinado. Não precisei pensar. Gostei. Foi para a memória. Esta é a regra fundamental deste computador que vive no corpo humano: só vai para a memória aquilo que é objeto de desejo. A tarefa primordial do 
professor: seduzir o aluno para que ele deseje e, desejando, aprenda.

O aluno da EJA, gostando da maneira como as disciplinas e as atividades são direcionadas, pode ter seu rendimento alterado para melhor, mas, do contrário, pode desistir, por isso o sentimento de impotência, fracasso e o desânimo devem ser evitados. Para tanto, o professor precisa alterar, ou até mesmo modificar, as atividades propostas assim que perceber qualquer desses sentimentos, a fim de que o aluno continue a caminhar sem vontade de parar.

Ainda durante o curso de graduação em Pedagogia, conheci a história de um aluno da EJA que voltou a estudar para incentivar o filho, que também havia abandonado a escola. Ele concluiu o Ensino Médio antes do filho, prestou o Exame Nacional de Ensino Médio (ENEM) e conseguiu fazer o curso de Engenharia Elétrica, que era seu sonho. $\mathrm{O}$ filho apenas concluiu o Ensino Médio e parou para constituir família, repetindo a história do pai, que hoje está concluindo a graduação. Em entrevista, o pai disse que recebeu muita motivação por parte dos professores e colegas, assim, se sentiu à vontade para seguir em frente, uma vez que percebeu o seu valor e a importância de sua contribuição à sociedade depois de graduado. Como visto, cabe ao professor o papel de estimulador:

Educar é mostrar a vida a quem ainda não a viu. O educador diz: "Veja" - e, ao falar, aponta. O aluno Olha na direção apontada e vê o que nunca viu. O seu mundo se espanta. Ele fica mais rico interiormente. $E$, ficando mais rico interiormente, ele pode sentir mais alegria e dar mais alegria - que é a razão pela qual vivemos. Vivemos para ter alegria e para dar alegria. O milagre da educação acontece quando vemos um mundo que nunca se havia visto (ALVES, 2003, p. 116)

O aluno de EJA citado anteriormente não sabia lidar com o computador e, por meio de atividades desenvolvidas pelo professor no laboratório de informática, foi levado a ter um novo olhar para as tecnologias, o que propiciou qualidade no aprendizado que favoreceu seu ingresso num curso superior. O professor de EJA pode utilizar o computador como um aliado à alfabetização. Por meio da produção de textos, por exemplo, em forma de cartas ou de e-mail, pode-se discutir as semelhanças e diferenças entre eles e as novas formas de comunicação a partir do uso das novas tecnologias. Abrirse-á um leque de discussões que podem ser trabalhados de forma transversalmente.

O professor pode levar o aluno a pensar em sua localização física e a virtual, assim como em suas possibilidades de enviar e receber cartas virtuais mesmo fora de casa, ou seja, por meio de um computador ou de um celular conectado à rede mundial de computadores. Outra forma interessante é trabalhar a mensagem pelo celular, que pode contribuir para a discussão da diferença entre o bilhete e a mensagem pelo aparelho móvel, levando o aluno a questionamentos sobre a tecnologia da comunicação e como simplificar o envio e recebimento do bilhete, entregue em mãos, trabalhando também a outra nomenclatura para o mesmo gênero textual.

Ao alfabetizar, o professor pode aproveitar e também trabalhar a inclusão digital e suas tecnologias como facilitadoras e também prazerosas. Ações para a inclusão do aluno nas tecnologias são bem vindas pelos estudantes, pois alguns podem não ter acesso ao computador conectado à rede mundial. Dessa forma, o professor apresenta a tecnologia a alguns e amplia os conhecimentos de outros, estabelecendo uma troca de saberes que deve ser articulada em sala de aula com alunos EJA. Rodrigues(1991, p. 66) fazalgumasconsiderações sobre o ato educativo, quando afirma que:

À medida que o professor, enquanto educador compreende a importância social do seu trabalho, a dimensão transformadora da sua ação, a importância social, cultural, coletiva 
e política da sua tarefa, o seu compromisso cresce.

Nem toda escola está equipada com equipamentos, como o computador, para que o professor trabalhe com seus alunos. Contudo, ele pode trabalhar com o celular, outra ferramenta de grande utilidade quando conectado à rede mundial de computadores. O aparelho pode acrescentar saberes que os alunos necessitam utilizar em seu dia a dia, como enviar mensagens, e-mails, fotos e outras ferramentas que cada aparelho oferece.

\section{Considerações Finais}

Existe um leque de possibilidades para o professor preparar o aluno da sala EJA para a posse de algumas habilidades e competências necessárias para a sua vida em sociedade com mais autonomia. Basta, apenas, pensar que o aluno EJA já traz bastante bagagem, mas nem sempre sabe como utilizá-la e cabe ao educador orientar o caminho para a apropriação do conhecimento, alfabetizando e letrando, em um conjunto ideal de ensino aprendizagem.

O professor necessita de qualificação para saber o que, para que e por que trabalhar cada atividade.Porisso,éimportantetomarconsciência da relevância de como levar conhecimento que não por intermédio de monólogos cansativos, mas por meio de aulas participativas e lúdicas, pois os adultos, ao contrário das crianças:

a) necessitam de saber o motivo pelo qual devem realizar certas aprendizagens; b) aprendem melhor experimentalmente; c) concebem a aprendizagem como resolução de problemas; d) aprendem melhor quando o tópico possui valor imediato e os motivadores mais potentes para a aprendizagem são internos (NOGUEIRA, 2004, p. 5).

A indisciplina e a falta de interesse dos alunos são constantes reclamações, por parte dos docentes, que podem acarretar desânimo. Veiga (2002, p. 63) destaca o professor diante de situações adversas dentro de uma sala de aula.

A impotência diante dos problemas educacionais tem se constituído no sentimento mais freqüente entre os educadores que, corroídos pelo "cansaço pedagógico" e principalmente pro uma grande angústia, anseiam chegar ao como, às receitas ou aos possíveis modelos de um paradigma que melhor explique o fazer educativo. Mas pelo fato de não terem sido "gestados" e gestados no cotidiano, acabam não sendo absorvidos, vividos. Em muitos dos casos esse descompasso não é percebido com nitidez e muito menos em suas causas, mas traz o embate entre o paradigma instalado e outro(s) que a realidade solicita.

Portanto, o professor tem que estar preparado para atender aos diversos níveis de dificuldades e/ou conhecimentos. Isso porque os alunos de EJA são sujeitos pensantes, autônomos e com sua própria cultura e conceito formados. $\mathrm{O}$ facilitador de aprendizagem, segundo o modelo da Andragogia, não é um ser ausente durante o processo de alfabetização do adulto e, sim, um agente norteador que leva o aluno a refletir e a se tornar um pesquisador autônomo, que motiva o aluno da EJA a levar adiante seus projetos, pois aprende a projetar seus sonhos transformando assim o fracasso escolar em contínua e eterna busca pelo conhecimento.

Para Veiga (2002, p. 132)., a busca por aprender deve ser transformada em atitude:

Está aí um desafio teórico-prático que a nova orientação paradigmática gera: o desafio de colocarmo-nos diante do instrumental da pesquisa e da educação, numa atitude prático-reflexiva, criando e recriando instrumentos que viabilizam a convergência entre o refletir e o agir conscientes. E de fazer do espaço educativo um lugar privilegiado de aprendizagem. Lugar este que possibilite aos sujeitos da educação uma nova relação com 
o conhecimento. Relação em que a busca de aprender transforma-se numa atitude práticoreflexiva que leva, portanto, ao conhecimento.

Assim, tanto a Pedagogia como a Andragogia podem contribuir, cada uma a seu tempo, com a alfabetização de adultos, respeitando os alunos e suas capacidades cognitivas, lançando constantes desafios para uma educação inclusiva. Um verdadeiro e completo resgate social, não apenas no sentido de devolver ao aluno EJA o tempo perdido, mas no âmbito da transformação de sonhos em realidade, fixando seus ideais naquilo que a sociedade espera e quer de um cidadão, ou seja, um protagonista da sua própria história.

\section{Referências}

ALVES, R. Conversas sobre educação. Campinas, SP: Verus, 2003.

RODRIGUES, N. Da mistificação da escola à escola necessária. São Paulo: Cortez, 1991.

FREIRE, P. Pedagogia do Oprimido. Rio de Janeiro: Paz e Terra, 2006.

NOGUEIRA, S. M. A Andragogia: que contributos para a prática educativa?. Linhas: Revista do Programa de Mestrado em Educação e Cultura, Florianópolis, v. 5, n. 2, p. 333-356, dez. 2004.

OLIVEIRA, A. B. A essência andragógica para empresas. Minnesota: land, 2011.

PICONEZ, S. C. B. Educação escolar de jovens e adultos. Campinas: Papirus, 2006.

SOARES, M. Letramento: um tema em três gêneros. Belo Horizonte: Autêntica, 2003. . Linguagem e escola: uma perspectiva social. São Paulo: Ática, 2008.

VEIGA, I. P. A. Projeto Político Pedagógico da escola: uma construção possível. Campinas: Papirus, 2002.

Submetido em 19 de novembro de 2012.

Aprovado em 7 de janeiro de 2013. 